\title{
Avaliação de diferentes processos de destoxificação sobre o valor nutricional e energético da torta de mamona para suínos
}

\author{
[Evaluation of different detoxification procedures on nutritional and energy value of
} castor bean cake for pigs]

\author{
T.R.G. Silva, ${ }^{1,3}$, L. A. F. Pascoal ${ }^{2,3}$, F. G. P. Costa ${ }^{3}$, T. D. D. Martins ${ }^{2}$, J. B. Silva Junior ${ }^{3}$, \\ M. R. Silva Neto ${ }^{3}$, P. H. Watanabe \\ ${ }^{1}$ Universidade Estadual de Goiás - São Luís de Montes Belos, GO \\ ${ }^{2}$ Universidade Federal da Paraíba, Bananeiras, PB \\ ${ }^{3}$ Programa de Pós-graduação - Universidade Federal da Paraíba, Areia, PB \\ ${ }^{4}$ Universidade Federal do Ceará, Fortaleza, CE
}

\begin{abstract}
RESUMO
O objetivo do presente estudo foi avaliar o valor nutricional e energético da torta de mamona destoxificada por diferentes métodos para suínos em crescimento. Foram utilizados 24 suínos machos, castrados, distribuídos em seis tratamentos, sendo uma ração referência e cinco rações testes $(75 \%$ da dieta referência e $25 \%$ das tortas de mamona) contendo a torta de mamona destoxificada pelos métodos do hidróxido de cálcio, da autoclavagem, do hidróxido de cálcio+ensilagem, da autoclavagem+ensilagem e da extrusão. As tortas de mamona submetidas aos processos de destoxificação com hidróxido de cálcio e autoclavagem resultaram em maior teor de proteína digestível. Para o valor de energia metabolizável, os processos de destoxificação com hidróxido de cálcio, autoclavagem, hidróxido de cálcio+ensilagem e extrusão não diferiram entre si. Considerando-se a valoração nutricional e energética da torta de mamona por meio dos processos de destoxificação, os métodos com uso de hidróxido de cálcio e autoclavagem são os mais eficientes.
\end{abstract}

Palavras-chave: alimento alternativo, digestibilidade, fator antinutricional, ricina

\begin{abstract}
The aim of this study was to evaluate the nutritional and energy value of castor bean cake detoxified by different methods for growing pigs. A total of 24 barrows was distributed in six treatments, being in a reference diet and 5 test diets ( $75 \%$ of the reference diet and $25 \%$ of castor beam cake) containing castor bean cake detoxified by the method of calcium hydroxide, autoclaving, calcium hydroxide + silage, autoclaving + silage and extrusion. Castor bean cake subjected to detoxification processes with calcium hydroxide and autoclaving resulted in higher content of digestible protein. For the metabolizable energy value, the process of detoxification with calcium hydroxide, autoclaving, calcium hydroxide+silage, and extrusion did not differ. Considering the nutritional and energy valuation of castor bean cake detoxified by different procedures, the methods using calcium hydroxide and autoclaving were the most efficient.
\end{abstract}

Keywords: alternative feedstuff, antinutritional factor, digestibility, ricin

\section{INTRODUÇÃO}

$\mathrm{Na}$ suinocultura, assim como em outros segmentos da produção animal, a nutrição é um dos fatores fundamentais de produção e representa cerca de $70 \%$ dos custos totais da atividade. Os ingredientes mais utilizados nas rações de suínos são o farelo de soja e o milho,

Recebido em 10 de novembro de 2016

Aceito em 3 de maio de 2017

*Autor para correspondência (corresponding author)

E-mail: leonardo@cchsa.ufpb.br constituindo em torno de 80 a $90 \%$ das rações, e são as principais fontes proteicas e energéticas das dietas, respectivamente (Ruiz et al., 2008), implicando a busca por possíveis substitutos a estes.

Nesse sentido, a procura por combustíveis renováveis tem aumentado o interesse no cultivo e no processamento de oleaginosas para 
produção de combustíveis como o biodiesel, bem como tem resultado na geração de resíduos, que podem ser utilizados na alimentação animal, agregando valor à produção (Madeira Júnior et al., 2011) e diminuindo o impacto ambiental pelo destino correto destes. Dentre os coprodutos da produção de biodiesel, a torta de mamona apresenta potencial para ser utilizada em rações por substituir fontes proteicas como o farelo de soja, desde que as limitações relacionadas à sua toxidez e alergenicidade sejam superadas (Severino, 2005). Assim, conhecer as características dos alimentos alternativos, incluindo os efeitos do tipo de processamento, principalmente quanto às formas de destoxificação e eliminação de fatores antinutricionais presentes neles, é importante para a adequada formulação das dietas.

Anadan et al. (2005) avaliaram a eficácia de diferentes métodos físicos e químicos de destoxificação da torta de mamona, utilizando métodos como a autoclavagem (15psi, 60min) e o tratamento com hidróxido de cálcio $(40 \mathrm{~g} / \mathrm{kg}$ de torta de mamona), e observaram que eles desnaturaram completamente a toxina. Já Furtado et al. (2012) afirmaram que a destoxificação da torta de mamona com o uso de calcário calcítico, ureia, fosfato bicálcico e autoclave não foi eficiente para promover a completa remoção da ricina, não resultando em melhora na digestibilidade dos nutrientes. Ao avaliarem diferentes métodos de destoxificação do farelo de mamona sobre a digestibilidade dos nutrientes para codornas de corte, Santos et al. (2015) verificaram efeito do tipo de processamento sobre a metabolizabilidade dos nutrientes, sugerindo a recuperação em etanol por 15 minutos, considerando-se a eficiência no processo de destoxificação e a aplicabilidade em processo industrial. Dessa forma, embora algumas metodologias tenham sido propostas, verifica-se variabilidade nos resultados e na eficiência do processo de destoxificação da torta de mamona (Akande e Odunsi, 2012), havendo também pouca informação a respeito dos efeitos do processamento desse ingrediente sobre a digestibilidade dos nutrientes para suínos.

Diante do exposto, o objetivo deste estudo foi avaliar os diferentes métodos de destoxificação da torta de mamona sobre a digestibilidade dos nutrientes e a metabolizabilidade da energia para suínos em crescimento. Foi realizado um experimento para determinar os coeficientes de digestibilidade dos nutrientes e energia metabolizável da torta de mamona destoxificada por diferentes processos para suínos.

\section{MATERIAL E MÉTODOS}

O ensaio foi realizado no Laboratório de Suinocultura, pertencente ao Departamento de Ciência Animal. Os protocolos experimentais utilizados neste estudo foram aprovados pela Comitê de Ética no Uso de Animais (CEUA, $n^{\circ}$ 20/2016) da Universidade Federal da Paraíba.

Foram utilizados 24 suínos machos, castrados, de mesma linhagem comercial (Agroceres ${ }^{\circledR}$ ), com peso médio inicial de $57,84 \pm 2,89 \mathrm{~kg}$, oriundos de granja comercial. Os animais foram distribuídos em delineamento de blocos ao acaso, com seis tratamentos, quatro repetições e um suíno por unidade experimental. Os tratamentos consistiram em uma ração referência e em cinco rações testes contendo a torta de mamona destoxificada pelo método do hidróxido de cálcio, da autoclave, do hidróxido de cálcio+ensilagem, da autoclave+ensilagem e da extrusão. A ração referência (Tab. 1) foi formulada à base de milho e farelo de soja, para atender as exigências nutricionais dos suínos de 50 a $70 \mathrm{~kg}$, de acordo com Rostagno et al. (2011).

As rações testes eram compostas por $75 \%$ da dieta referência e $25 \%$ das tortas de mamona submetidas aos diferentes processos de destoxificação. Para a destoxificação pelo método de hidróxido de cálcio, foi preparada uma solução $3 \mathrm{~g}$ de $\mathrm{CaO} / \mathrm{mL}$ de água, sendo esta adicionada à torta de mamona na concentração de $60 \mathrm{~g} / \mathrm{kg}$. Após a mistura, a torta foi coberta com lona plástica por oito horas para posterior utilização. Pelo processo de autoclavagem, a torta de mamona foi acondicionada em sacos de tecido e mantida à pressão de 1,23 (15psi), com temperatura média de $123^{\circ} \mathrm{C}$, durante 60 minutos. 
Tabela 1. Composição e valor nutricional da dieta referência

\begin{tabular}{cc|}
\hline Ingredientes & Dieta referência $(\mathrm{g} / \mathrm{kg})$ \\
Milho moído & 740,10 \\
Farelo de soja & 226,30 \\
Óleo de soja & 4,50 \\
Fosfato bicálcico & 9,70 \\
Calcário calcítico & 5,60 \\
Sal comum & 3,40 \\
BHT ${ }^{(1)}$ & 1,50 \\
Suplemento mineral e vitamínico ${ }^{(2)}$ & 4,00 \\
L-lisina HCl, & 3,20 \\
L-treonina & 0,90 \\
DL-metionina & 0,70 \\
L-triptofano & 0,10 \\
\hline Total & 1000,00 \\
\hline Composição calculada ${ }^{(3)}$ & 3230,00 \\
Energia digestível, kcal/kg & 17,07 \\
Proteína bruta, \% & 0,55 \\
Cálcio, \% & 0,28 \\
Fósforo disponível, \% & 11,65 \\
Fibra em detergente neutro, \% & 4,29 \\
Fibra em detergente ácido, \% & 0,95 \\
Lisina digestível, \% & 0,32 \\
Metionina digestível, \% & 0,62 \\
Treonina digestível, \% & 0,17 \\
Triptofano digestível, \% & \\
\hline
\end{tabular}

${ }^{1}$ Butil-hidroxitolueno. ${ }^{2}$ Suplemento vitamínico - quantidade por $\mathrm{kg}$ do produto: $2.500 .000 \mathrm{UI}$ de vitamina A, $500.000 \mathrm{UI}$ de vitamina D3, 50mg de biotina, 50mg de colina, $10000 \mathrm{mg}$ de niacina, 3000mg de pantotenato de cálcio, $7 \mathrm{mg}$ de vitamina B12, 1800mg de vitamina B2, 7500mg de vitamina E, $1000 \mathrm{mg}$ de vitamina K3. Suplemento mineral - quantidade por kg do produto: $40.000 \mathrm{mg}$ de ferro, $35.000 \mathrm{mg}$ de cobre, $20.000 \mathrm{mg}$ de manganês, $40.000 \mathrm{mg}$ de zinco, $360 \mathrm{mg}$ de cobalto, $840 \mathrm{mg}$ de iodo, $120 \mathrm{mg}$ de selênio.

${ }^{3}$ Valores nutricionais dos ingredientes propostos por Rostagno et al. (2011).

Tanto o processo com hidróxido de cálcio+ensilagem como o de autoclave+ ensilagem constituíram na ensilagem do material submetido previamente ao tratamento com hidróxido de cálcio e ensilagem, respectivamente. Para ambos, a ensilagem foi realizada com adição de $20 \%$ de água e inoculante enzimático microbiano comercial $\left(\right.$ Kera-Sil $\left.^{\circledR}\right)$ na dosagem recomendada para ensilagem de grãos úmidos $\left(4 \mathrm{~g}\right.$ ton $\left.^{-1}\right) \mathrm{e}$, posteriormente, armazenagem da torta em tambores de polietileno com capacidade para 200 litros por 30 dias.

No processo de destoxificação por extrusão, foi adicionado $1 \%$ de $\mathrm{CaO}$ na torta de mamona, que foi submetida à extrusão em temperatura de $105^{\circ} \mathrm{C}$. O tempo de permanência na extrusora foi de 90 segundos. A torta de mamona foi enviada para o secador e, em seguida, resfriada por 30 minutos.

Inicialmente os animais foram pesados e alojados nas gaiolas para estudos metabólicos. O período experimental foi de 12 dias, sendo sete dias de adaptação dos animais às dietas e cinco dias de coleta de fezes e urina. Durante o período de adaptação, foi determinada a quantidade total diária de ração de acordo com o consumo dos animais, baseado no peso metabólico $\left(\mathrm{kg} \mathrm{PV}^{0,75}\right)$ de cada unidade experimental.

Durante o ensaio, o arraçoamento foi realizado duas vezes ao dia, às oito e às 18 horas. As rações foram pesadas e umedecidas na proporção de 1:1, para evitar o desperdício, reduzir a pulverulência e facilitar o consumo, sendo fornecida água à vontade.

$\mathrm{O}$ óxido férrico $\left(\mathrm{Fe}_{2} \mathrm{O}_{3}\right)$ foi utilizado como marcador fecal para determinar o início e o final do período de coleta, sendo as fezes coletadas duas vezes ao dia, pesadas, sendo posteriormente mantidas congeladas. A urina foi coletada uma vez ao dia, em baldes plásticos, onde eram adicionados, no início de cada dia de coleta, $20 \mathrm{~mL}$ de solução de $\mathrm{HCl}(2 \mathrm{~N})$, com o objetivo de não permitir a perda do nitrogênio e a proliferação de bactérias. $\mathrm{O}$ volume de urina 
produzido foi mensurado, e retirou-se uma alíquota de $20 \%$, que foi mantida congelada. Ao final do experimento, as fezes de cada suíno foram descongeladas, homogeneizadas, e uma amostra representativa foi retirada, para determinação da matéria pré-seca, sendo, em seguida, moída em moinho tipo faca (MA340, Marconi, Piracicaba - Brasil) com peneira com crivo de $1 \mathrm{~mm}$, para realização das análises laboratoriais.

Os ingredientes que fizeram parte da composição das dietas experimentais (milho, farelo de soja e tortas de mamona destoxificadas pelos diferentes processos), as dietas e as fezes coletadas no ensaio de digestibilidade foram analisados, sendo determinados os teores de matéria seca, proteína bruta, extrato etéreo, matéria mineral e matéria orgânica de acordo com AOAC (Official..., 2005). A energia bruta dos ingredientes, rações, fezes e urina foram determinadas em bomba calorimétrica tipo Parr Americano (Parr 6400, Illinois - EUA). As análises de fibra em detergente neutro e de fibra em detergente ácido foram realizadas conforme descrito por Van Soest et al. (1991).

A partir dos valores de matéria seca, matéria orgânica, proteína bruta, extrato etéreo, e energia bruta, determinados pelas análises, foram calculados os coeficientes de digestibilidade aparente dos nutrientes e da energia, os de metabolizabilidade da energia, os teores de nutrientes digestíveis e a energia digestível e metabolizável dos ingredientes testados e das dietas, utilizando-se as fórmulas descritas em Sakomura e Rostagno (2007).

Os dados obtidos no ensaio foram analisados quanto à distribuição dos erros (teste de Cramer Van-Misses a 5\%) segundo Everitt (1998); estes, atendendo as pressuposições estatísticas, foram submetidos à análise de variância, e foi aplicado o teste de Tukey a $5 \%$ de significância.

\section{RESULTADOS E DISCUSSÃO}

Os valores de composição química da torta de mamona (Tab. 2) foram semelhantes aos relatados por outros autores (Beltrão, 2002; Faria Filho et al. 2010; Adedeji, 2013). A composição química das tortas de mamona submetidas à destoxificação pode sofrer variações em função dos processos utilizados para suas obtenções, principalmente quando submetidas aos processos que envolvem calor e condições anaeróbicas de fermentação.

Quando comparados os valores nutricionais das tortas de mamona destoxificadas em relação às não destoxificadas, verifica-se que não há alteração nos valores nutricionais e que os valores de proteína bruta e energia das tortas submetidas aos métodos que utilizam calor, como a autoclavagem e a extrusão, são superiores aos demais métodos. Isto pode ser explicado provavelmente porque o valor de energia pode estar correlacionado com $\mathrm{o}$ conteúdo de matéria orgânica, e considerando o aumento no teor de matéria mineral nos tratamentos com adição de hidróxido de cálcio, houve redução na energia bruta da torta de mamona submetida ao processo de destoxificação química.

Não foi observado efeito para os coeficientes de digestibilidade da matéria seca entre os diferentes métodos de destoxificação (Tab. 3). No entanto, as tortas submetidas aos processos de destoxificação por autoclavagem com posterior ensilagem e pelo processamento de extrusão apresentaram menores $(\mathrm{P}<0,05)$ coeficientes de digestibilidade da proteína bruta, quando esses métodos foram comparados aos demais. As alterações nas propriedades físicas e químicas dos alimentos submetidos ao calor dependem das características do tratamento térmico e são utilizadas como estratégia para melhorar a qualidade do produto (Th, 1990). No entanto, o processo de ensilagem posterior ao processo de autoclavagem não favoreceu $o$ aproveitamento da proteína, possivelmente devido à maior perda por efluentes, indicando que a estabilização do processo fermentativo não foi alcançada no período avaliado. Em relação ao processo de extrusão, observa-se que fatores envolvidos, como a força de cisalhamento, a pressão, a temperatura e a umidade, podem modificar as proteínas, ocasionando diminuição na digestibilidade dessa fração devido aos efeitos da desnaturação, ao reordenamento molecular ou à complexação com açúcares (Bertipaglia et al., 2008). 
Tabela 2. Composição nutricional das tortas de mamona submetidas aos diferentes processos de destoxificação

\begin{tabular}{|c|c|c|c|c|c|c|}
\hline \multirow[b]{2}{*}{$\begin{array}{l}\text { Nutrientes e } \\
\text { energia }^{1}\end{array}$} & \multicolumn{6}{|c|}{ Processos de destoxificação da torta de mamona } \\
\hline & $\begin{array}{c}\text { Não- } \\
\text { destoxificada }\end{array}$ & $\begin{array}{l}\text { Hidróxido de } \\
\text { cálcio }\end{array}$ & Autoclavagem & $\begin{array}{l}\text { Hidróxido de } \\
\text { cálcio }+ \\
\text { ensilagem }\end{array}$ & $\begin{array}{c}\text { Autoclavagem } \\
+ \\
\text { ensilagem }\end{array}$ & Extrusão \\
\hline Matéria mineral, $\%$ & 6,64 & 14,34 & 7,22 & 14,39 & 6,47 & 7,69 \\
\hline Matéria orgânica, \% & 93,36 & 85,66 & 92,78 & 85,61 & 93,53 & 92,31 \\
\hline Proteína bruta, \% & 30,58 & 29,28 & 32,96 & 26,96 & 32,36 & 31,41 \\
\hline $\mathrm{FDA}^{3}, \%$ & 23,20 & 21,39 & 24,49 & 21,54 & 26,18 & 33,31 \\
\hline $\begin{array}{l}\text { Energia bruta, } \\
\mathrm{kcal} / \mathrm{kg}\end{array}$ & 4587,93 & 4392,31 & 4784,24 & 4348,62 & 4560,59 & 4918,99 \\
\hline \multicolumn{7}{|l|}{ Aminoácidos, $\%$} \\
\hline Metionina & 0,470 & 0,480 & 0,521 & 0,438 & 0,588 & 0,513 \\
\hline Triptofano & 0,336 & 0,308 & 0,347 & 0,284 & 0,351 & 0,331 \\
\hline Arginina & 3,011 & 3,014 & 3,306 & 2,799 & 3,458 & 3,142 \\
\hline Isoleucina & 1,242 & 1,249 & 1,361 & 1,144 & 1,372 & 1,336 \\
\hline Leucina & 1,781 & 1,866 & 1,953 & 1,641 & 1,953 & 1,923 \\
\hline Valina & 1,494 & 1,486 & 1,641 & 1,372 & 1,648 & 1,602 \\
\hline Histidina & 0,580 & 0,610 & 0,624 & 0,569 & 0,651 & 0,633 \\
\hline Fenilalanina & 1,155 & 1,187 & 1,254 & 1,051 & 1,260 & 1,253 \\
\hline Glicina & 1,236 & 1,249 & 1,353 & 1,145 & 1,365 & 1,317 \\
\hline Serina & 1,480 & 1,519 & 1,629 & 1,247 & 1,640 & 1,420 \\
\hline Prolina & 0,999 & 1,078 & 1,107 & 0,949 & 1,121 & 1,114 \\
\hline Alanina & 1,196 & 1,235 & 1,314 & 1,107 & 1,324 & 1,302 \\
\hline Ácido aspártico & 2,506 & 2,601 & 2,762 & 2,364 & 2,793 & 2,778 \\
\hline
\end{tabular}

${ }^{1}$ Valores com base na matéria natural. ${ }^{2} \mathrm{FDN}$ - fibra em detergente neutro; ${ }^{3} \mathrm{FDA}$ - fibra em detergente ácido.

Tabela 3. Coeficientes de digestibilidade (CD) e metabozabilidade (CM) da torta de mamona destoxificada por diferentes processos para suínos

\begin{tabular}{ccccccc}
\hline & \multicolumn{5}{c}{ Processos de destoxificação da torta de mamona } \\
\cline { 2 - 5 } & $\begin{array}{c}\text { Hidróxido de } \\
\text { cálcio }\end{array}$ & Autoclavagem & $\begin{array}{c}\text { Hidróxido de } \\
\text { cálcio }+ \\
\text { ensilagem }\end{array}$ & $\begin{array}{c}\text { Autoclavagem }+ \\
\text { ensilagem }\end{array}$ & Extrusão & CV, \% \\
\hline CDMS, \% & 52,59 & 53,71 & 52,67 & 43,22 & 52,92 & 13,16 \\
CDPB, \% & $61,18 \mathrm{a}$ & $65,68 \mathrm{a}$ & $63,24 \mathrm{a}$ & $53,87 \mathrm{~b}$ & $54,07 \mathrm{~b}$ & 3,97 \\
CDEB, \% & $64,09 \mathrm{ab}$ & $69,00 \mathrm{a}$ & $64,94 \mathrm{ab}$ & $51,09 \mathrm{~b}$ & $62,44 \mathrm{ab}$ & 11,67 \\
CMEB, \% & $62,54 \mathrm{a}$ & $68,12 \mathrm{a}$ & $59,32 \mathrm{ab}$ & $40,82 \mathrm{~b}$ & $60,18 \mathrm{a}$ & 12,22 \\
\hline
\end{tabular}

${ }^{1}$ MS - matéria seca; PB - proteína bruta; ED - energia digestivel e EM - energia metabolizável. Médias seguidas da mesma letra na linha não diferem entre si pelo teste de Tukey $(\mathrm{P}>0,05) .{ }^{2}$ Valores com base na matéria natural.

Em relação aos valores dos coeficientes de metabolizabilidade da energia bruta, foi verificado $(\mathrm{P}<0,05)$ que o processamento de autoclavagem e a posterior ensilagem resultaram no menor valor para essa variável quando comparados aos tratamentos com adição de hidróxido de cálcio, autoclavagem e extrusão.

Embora não tenha sido observado efeito dos diferentes processos de destoxificação sobre a matéria seca digestível da torta de mamona $(\mathrm{P}>0,05)$, observou-se que as formas de destoxificação por hidróxido de cálcio, autoclavagem e autoclavagem+ensilagem resultaram em maior valor de proteína digestível $(\mathrm{P}<0,05)$, em relação aos outros métodos (Tab. 4). Observou-se também menor valor de energia digestível da torta de mamona submetida ao processamento por autoclavagem+ensilagem $(\mathrm{P}<0,05)$ quando comparado ao processo de autoclavagem, não diferindo dos demais tratamentos. Para a energia metabolizável, observou-se que os processos de destoxificação por hidróxido de cálcio e autoclavagem 
apresentaram maiores valores em comparação ao método por autoclavagem+ensilagem, não diferindo do processo de hidróxido de cálcio+ensilagem.

A ricina é uma glicoproteína composta por duas cadeias ligadas por ligação dissulfídica, sendo sua toxicidade potencializada por aglutininas, ricinina e compostos alergênicos (Akande et al., 2016). Porém, a ricina é resistente à ação de proteinases endógenas, sendo observado que a atividade da tripsina resulta ainda em peptídeos que também apresentam toxicidade (Lugnier et al.,1980). Nesse sentido, dentre os métodos avaliados, observou-se que o processo com uso de hidróxido de cálcio e a autoclavagem ocasionaram melhores digestibilidade da fração proteica e metabolizabilidade da energia em relação aos demais tratamentos. No entanto, ao se considerarem os custos envolvidos no processo de autoclavagem, bem como a quantidade máxima a ser processada ser limitada pela capacidade do equipamento utilizado, a destoxificação da torta de mamona com hidróxido de cálcio apresenta-se vantajosa. Embora Oliveira et al. (2010) tenham observado que a efetividade de detoxificação do farelo de mamona com hidróxido de cálcio foi acima de $60 \%$, de acordo com Balieiro Neto et al. (2007), o hidróxido de cálcio pode reduzir os constituintes da parede celular por hidrólise alcalina e contribuir para a preservação de nutrientes solúveis, melhorando, assim, a digestibilidade.

Tabela 4. Matéria seca, proteína bruta, energia digestível e metabolizável da torta de mamona destoxificada por diferentes processos para suínos

\begin{tabular}{|c|c|c|c|c|c|c|}
\hline \multirow[b]{2}{*}{$\begin{array}{l}\text { Nutrientes e } \\
\text { energia }\end{array}$} & \multicolumn{5}{|c|}{ Processos de destoxificação da torta de mamona } & \multirow[b]{2}{*}{$\mathrm{CV}, \%$} \\
\hline & $\begin{array}{l}\text { Hidróxido de } \\
\text { cálcio }\end{array}$ & Autoclavagem & $\begin{array}{c}\text { Hidróxido de } \\
\text { cálcio }+ \\
\text { ensilagem }\end{array}$ & $\begin{array}{c}\text { Autoclavagem } \\
+ \\
\text { ensilagem }\end{array}$ & Extrusão & \\
\hline MS, $\%$ & 46,43 & 47,13 & 47,48 & 39,35 & 47,28 & 13,14 \\
\hline $\mathrm{PB}, \%$ & $22,29 \mathrm{a}$ & $24,67 \mathrm{a}$ & $18,91 \mathrm{~b}$ & $19,14 b$ & $19,00 \mathrm{~b}$ & 4,00 \\
\hline $\mathrm{ED}, \mathrm{kcal} / \mathrm{kg}$ & $3188,7 \mathrm{ab}$ & $3762,2 \mathrm{a}$ & $3132,8 \mathrm{ab}$ & $2559,4 \mathrm{~b}$ & $3437,5 \mathrm{ab}$ & 12,22 \\
\hline $\mathrm{EM}, \mathrm{kcal} / \mathrm{kg}$ & $3111,5 \mathrm{a}$ & $3714,30 \mathrm{a}$ & $2862,0 \mathrm{ab}$ & $2044,6 b$ & $3313,2 \mathrm{a}$ & 13,07 \\
\hline
\end{tabular}

${ }^{1}$ MS - matéria seca; PB - proteína bruta; ED - energia digestivel e EM - energia metabolizável. Médias seguidas da mesma letra na linha não diferem entre si pelo teste de Tukey $(\mathrm{P}>0,05) .{ }^{2}$ Valores com base na matéria seca.

Além disso, de acordo com o valor energético da torta de mamona, observa-se que esse ingrediente apresenta maior digestibilidade dos nutrientes e energia metabolizável em relação ao farelo de mamona (Matos Júnior et al., 2011), independentemente do processo de destoxificação, devido ao teor de extrato etéreo residual presente. Dessa forma, considerando também a composição aminoacídica desse ingrediente, observa-se a possibilidade de uso dele como substituto parcial ao farelo de soja em rações (Silva et al., 2010). Quanto ao perfil de aminoácidos, a torta de mamona apresenta maior teor de metionina e valores próximos para treonina e valina em relação à soja em grão, embora o nível de lisina seja inferior (Annongu e Joseph, 2008), sendo recomendados os processos de destoxificação com adição de hidróxido de cálcio ou autoclavagem para melhor potencializar seu uso na alimentação de suínos, possibilitando a inclusão de até $10 \%$ de torta de mamona em rações para suínos nas fases de crescimento e terminação (Uechiewcharnkit e Kanthapanit, 1997).

\section{CONCLUSÕES}

Considerando-se a valorização nutricional e energética da torta de mamona a partir dos processos de destoxificação, os métodos com uso de hidróxido de cálcio e autoclavagem foram os mais eficientes.

\section{AGRADECIMENTOS}

Ao $\mathrm{CNPq}$, pelo financiamento do projeto de pesquisa, e à OLVEQ - Indústria e Comércio de Óleos Vegetais Ltda., pela doação da torta de mamona utilizada nos ensaios.

\section{REFERÊNCIAS}

ADEDEJI, O.S. The effect of different levels of dehusked castor seeds (Ricinus communis) on laying hens. Trans. J. Sci. Tech., v.3, p.25-31, 2013

AKANDE, T.O.; ODUNSI, A.A. Nutritive value and biochemical changes in broiler chickens fed detoxified castor kernel cake based diets. Afr. J. Biotec., v.11, p.2904-2911, 2012 
AKANDE, T.O.; ODUNSI, A.A.; AKINFALA, E.O. Review of nutritional and toxicological implications of castor bean (Ricinus communis L.) meal in animal feeding systems. J. Anim. Phys. Anim. Nutr., v.100, p.201-210, 2016.

ANANDAN, S.; KUMAR, A.G.K.; GHOSH, J. et al. Effect of different physical and chemical treatments on detoxification of ricin in castor cake. Anim. Feed Sci. Tech., v.120, p.159-168, 2005.

ANNONGU, A.A.; JOSEPH, J.K. Proximate analysis of castor seeds and cake. J. Appl. Sci. Environ. Manage., v.12, p.39-41, 2008.

BALIEIRO NETO, G.; SIQUEIRA, G.R.; REIS, R.A. et al. Óxido de cálcio como aditivo na ensilagem de cana-de-açúcar. Rev. Bras. Zootec., v.36, p1231-1239, 2007.

BELTRÃO, N.E.M. Torta de Mamona (Ricinus communis L.): fertilizante e alimento. Campina Grande: Embrapa Algodão, 2002. (Comunicado Técnico, 171). Disponível em: $<$ http://www.infoteca.cnptia.embrapa.br/bitstream/CN PA/19606/1/ COMTEC171.pdf>. Acessado em: 15 ago. 2013.

BERTIPAGLIA, L.M.A.; MELO, G.M.P.; SUGOHARA, A. et al. Alterações bromatológicas em soja e milho processados por extrusão. Rev. Bras. Zootec., v.37, p.2003-2010, 2008.

EVERITT, B.S. The Cambridge dictionary of statistics. Cambridge: Cambridge University Press, 1998. 360p.

FARIA FILHO, D.E.; DIAS, A.N.; BUENO, C.F.D.; MATOS JÚNIOR, J.B.; COUTO, F.A.P. Subprodutos da mamona na alimentação de aves. Avicultura, n.33, $2010 . \quad$ Disponível em http://www.avisite.com.br/cet/img/20100127_mamona .pdf. Acessado em: 22 mar. 2014.

FURTADO, R.N.; CARNEIRO, M.S.S.; CÂNDIDO, M.J.D. et al. Valor nutritivo de dietas contendo torta de mamona submetida a métodos alternativos de destoxificação para ovinos. Arq. Bras. Med. Vet. Zootec., v.64, p.155-162, 2012.

LUGNIER, A.A.; CREPPY, E.E.; DIRHEIMER, G. Ricin, the toxic protein of the castor-oil plant (Ricinus communis L). Structure and properties. Pathol. Biol., v.28, p.127-139, 1980.

MADEIRA JÚNIOR, J.V.; MACEDO, J.A.; MACEDO, G.A. Detoxification of castor bean residues and the simultaneous production of tannase and phytase by solid-state fermentation using Paecilomyces variotti. Bioresource Tech., v.102, p.7343-7348, 2011.
MATOS JÚNIOR, J.B.; DIAS, A.N.; BUENO, C.F.D. et al. Metabolizable energy and nutrient digestibility of detoxified castor meal and castor cake for poultry. Rev. Bras. Zootec., v.40, p.2439-2442, 2011.

OFFICIAL methods of analysis. 18.ed. Gaithersburg: AOAC, 2005. 1141p.

OLIVEIRA, A.S.; CAMPOS, J.M.S.; OLIVEIRA, M.R.C. et al. Nutrient digestibility, nitrogen metabolism and hepatic function of sheep fed diets containing solvent or expeller castorseed meal treated with calcium hydroxide. Anim. Feed Sci. Tech., v.158, p.15-28, 2010.

ROSTAGNO, H.S.; ALBINO, L.F.T.; DONZELE, J.L. et al. Tabelas brasileiras para aves e suínos: composição dos alimentos e exigências nutricionais. 3.ed. Viçosa: UFV, 2011. 252p.

RUIZ, U.S.; THOMAZ, M.C.; HANNAS, M.I. et al. Complexo enzimático para suínos: digestão, metabolismo, desempenho e impacto ambiental. Rev. Bras. Zootec., v.37, p.458-468, 2008.

SAKOMURA, N.K.; ROSTAGNO, H.S. Métodos de pesquisa em nutrição de monogástricos. Jaboticabal: FUNEP, 2007. 283p.

SANTOS, P.A.; LUDKE, M.C.M.M.; LUDKE, J.U. et al. Characterization and digestibility of detoxified castor oil meal for japanese quails. Rev. Bras. Cienc. Avicul. v.17, p.65-72, 2015.

SEVERINO. L.S. O que sabemos sobre a torta de mamona. Campina Grande: Embrapa Algodão, 2005. 31p. (Documento 134).

SILVA, D.C.; ALVES, A.A.; VASCONCELOS, V.R. et al. Metabolismo dos compostos nitrogenados em ovinos alimentados com dietas contendo farelo de mamona destoxificado. Acta Sci., Anim. Sci. v.32, p.219-224, 2010.

$\mathrm{TH}$, J. Residence time distributions in twin-screw cooking extruders. In: SPIESS, W.E.L.; SCHUBERT, H. (Eds.). Engineering and food advanced process. New York: Elsevier Applied Science, 1990. v.3, p.290-297.

UECHIEWCHARNKIT, K.; KANTHAPANIT, C. Effects of various levels of detoxified and deallergenized castor meal ration on growth performance and carcass characteristics of fattening swine. Thammasat. Int. J. Sci. Tech., v.2, p.56-60, 1997.

VAN SOEST, P.J.; ROBERTSON, J.B.; LEWIS, B.A. Methods for dietary fiber, neutral detergent fiber, and nonstarch polysaccharides in relation to animal nutrition. J. Dairy Sci., v.74, p.3583-3597, 1991. 